\title{
Effects of Height and Plan Geometry on the Costs of Tunnel Form Residential Buildings
}

\author{
Zeynep Yeşim Ilerisoy ${ }^{1 *}$, Mehmet Emin Tuna \\ ${ }^{1}$ Department of Architecture, Faculty of Architecture, Gazi University, Eti Mah. Yükseliş Sok. No 5 Maltepe, 06560 Ankara, Turkey \\ * Corresponding author, e-mail: zyharmankaya@gazi.edu.tr
}

Received: 10 April 2018, Accepted: 14 June 2018, Published online: 15 June 2018

\begin{abstract}
Tunnel form systems, which are industrialised construction systems developed in the last century, are widely used in reinforced concrete projects. Accurate determination of the costs of the building properties in the design phases of construction with the tunnel form system can lead to lower construction costs. The purpose of this study is to examine the cost variations resulting from changes in geometrical characteristics of buildings in the architectural design phase. The research was carried out on residential projects, which have the biggest share in the construction sector. Six housing projects with different plan geometries were designed, and these projects were examined for nine different numbers of floors. The study aims to reveal the extent to which both the plan shape and the number of floors influence the building costs. During the design phase, recommendations are given for reducing the building costs and finding the optimal form. It has been shown that tunnel form projects are not cost-effective in low-rise buildings and after a certain height. Furthermore, when different geometries are examined, the most economical cost is obtained in square form, and the cost increases as the two dimensions in plan plane move away from each other. As a result, the data obtained from this study will provide a better assessment of the relationship between building properties and unit cost in buildings constructed with tunnel form systems.

Keywords
\end{abstract}

tunnel form, cost analysis, plan geometry, building height

\section{Introduction}

Production of residential buildings, which constitutes a large share of construction investments, needs to be met in the most economic way. However, the developments in housing construction in recent years, including the application of new building materials and building styles, the growth of houses, and the application of different building geometries, make it difficult to reach a sustainable decision on construction costs. Understanding the connections between structural elements, their shapes, development and features have a much greater significance than in the past (Fülöp, 2012). To calculate the estimated building cost of any project, the most widely used method is to multiply the total building area with the approximate unit building costs provided by government ministries. However, this approximate calculation method does not consider the changing physical and geometrical properties of the designed structures. Previous studies, such as Bostancioğlu (1999), Ibrahim (2007), Ferry and Brandon (2007), and Belniak et al. (2013), pointed out that design decisions taken during the architectural design phase significantly affect the building cost. Design plays a very important role in architecture, not just aesthetically, but technically. As technology evolves and software becomes more powerful, it enables architects to explore new possibilities (Fülöp, 2012). Maver (1970) and Pena and Parshall (2001) defined architectural design as trial and error processes in which physical, aesthetic, functional, and economic variables are involved. Architectural design is the phase in which the various features of the structure are determined, and important decisions are taken on building properties that affect the cost of the building such as size, location, construction technology, materials, workmanship, and quality. If the decisions taken at this stage, where the chances of affecting the building cost are highest, are based on the correct information using the right methods, it will result in more effective designs and lower building costs (Bostancıŏlu, 1999). This study aims to examine the cost variations resulting from the changes in 
geometrical characteristics of buildings in the architectural design phase. The research is based on housing projects, which have the biggest share in the construction sector.

The most common construction type of residential buildings, one of the important working areas of architecture, are reinforced concrete applications. For these applications, formwork systems are among the key factors determining the success regarding safety and cost. Different formwork systems are used according to the load-bearing system design of structures. In general, traditional/conventional formworks are used when the load-bearing system is framed, and tunnel formwork systems are used when the load-bearing system is a shear wall system.

The tunnel-form system is an industrialised construction technique in which structural walls and slabs are cast (in situ) simultaneously using steel forms composed of vertical and horizontal panels set at right angles (Kalkan and Yüksel, 2007). This industrialised construction system is widely used in the construction industry due to the increased building production speed, more practical use, longer service life and high-quality production. However, when a review of the literature is carried out to clarify the relationship between geometrical properties of buildings and cost, it is seen that most of the studies do not involve tunnel form systems. Rather they were carried out on reinforced concrete or composite structures produced with traditional / conventional formworks.

In the design phases of today's structures, it is especially important to determine the relationship between tunnel form systems that are used intensively in to meet housing needs and costs. Çıracı (1996) and Türkel and Ergen (2016) investigated the variations in the cost of existing housing projects built with tunnel form systems for different floor areas and heights. Investigations on the effects of building properties on the cost of the buildings show that two main methods are followed (Warszawski, 2003). In the first method, statistical analyses are made according to different design alternatives using real cost values of sample buildings having different design features such as height, floor area and plan form. For the validity of the statistical analysis, it is necessary to obtain sufficient data for the cost of structures. Studies that are related to tunnel form systems were realised by this method (Çırac1, 1996; Türkel and Ergen, 2016). In the second method, the building design models are constructed by making controlled changes in the examined design features such as height, plan form and material; then the financial effects of different design alternatives are analysed. The most significant difficulty encountered in this method is reflecting the typical building characteristics that would represent the general aspects of existing buildings, and accordingly, require a long design process (Warszawski, 2003). However, there are no studies in the literature on the second method using tunnel form projects. Therefore, in this study, the second method was followed. A comprehensive research group was created by the authors from housing projects designed by the tunnel form system, with only specified design variables being differentiated.

Previous studies show that the most important design variables affecting the total cost are, in order: plan shape, complexity, number of floors, floor height, and service requirements of construction (Safiki et al., 2015). In this study, the number of building floors and plan shapes that are important in the mentioned order are considered as main variables. Investigating the previous studies on the effect of numbers of floors, which is one of the main parameters of this study, Tregenza (1972) and Ferry and Brandon (2007) indicated that total cost of the building increases as the number of floors increases. Newton (1982), Çıracı (1996), Harmankaya and Tuna (2011), Türkel and Ergen (2016) have stated that the unit cost decreases first with the increase of the floor number and then increases again in a U-shaped relationship. In the literature survey of the other main parameter, plan shape, Ibrahim (2007) indicated that the complexity and slenderness of the shape of the plan significantly increased the costs. Bostancioğlu (1999) stated that as the plan shape differs from square and rectangle, the load-bearing system becomes complicated and the cost increases accordingly. Many studies predicted that the costs of buildings with simple plan shapes became lower (Seeley, 1996; Wing, 1999; Ashworth et al., 2013). Ashworth et al. (2013) stated that there is no complete freedom when the building is planned according to the conditions of the land to be built; plan decisions should be balanced in terms of cost in the most appropriate way.

In the light of all the literature research, the aim is to show to what extent the plan shape of the structure (simple or compound geometry), built with the tunnel formwork system, affects the building cost. The effect of floor number on the building cost is also considered as a second parameter. The models with simple geometrical shapes of square and rectangle as well as compound shapes having the form of $\mathrm{H}, \mathrm{U}, \mathrm{T}$ and $\mathrm{L}$ with identical net floor area and architectural solution are designed. The effect of the plan geometry on the cost is examined at a precise scale on those six plan shapes by differentiating the parameters 
in a controlled way. This study aims to make a comparative evaluation with similar architectural housing projects. The important points are the construction of the projects in accordance with the standards, and keeping the architectural solutions, the net floor areas of the apartments and the buildings' footprint areas as constant as possible to protect the realism of the work. All projects were designed to be two apartments on each floor, with the same function layout and architecturally meaningful and usable spaces, according to today's standards. As a result, in this study, the intention is to shed light on the production of tunnel form residential structures at minimum cost.

\section{Method of Study}

To investigate the effect of the design decisions taken in the architectural design phase on the building costs, a research group was formed by changing geometrical characteristics of the buildings to be examined. However, since the variables affecting the cost are too diverse, the scope of the current study is limited. There are factors that the designer cannot intervene such as the dependent factors in the region and settlement; the climatic conditions, regional conditions, land characteristics, and various laws are not considered. These factors in all the projects to be examined are assumed to be the same.

Then, within the scope of the study, the number of apartments on each floor is fixed at two in the housing projects to reach the maximum number of forms. All projects have a standard footprint area of approximately $400-407 \mathrm{~m}^{2}$. The designed apartment solutions are assembled in different shapes around a centre. A total of six residential projects were designed with simple geometrical shapes of $20 \mathrm{~m} \times 20 \mathrm{~m}$ square and $10 \mathrm{~m} \times 40 \mathrm{~m}$ rectangle and compound geometric shapes consisting of $\mathrm{L}, \mathrm{T}, \mathrm{H}$ and $\mathrm{U}$ forms (Fig. 1). Geometrically different projects were created in accordance with housing standards and architectural solutions; net floor areas, footprint areas are kept as constant as possible. In the binary forms of L-T and $\mathrm{H}-\mathrm{U}$ from the combined geometries, the layouts of architectural and structural elements are the same, and their differences are obtained by shifting certain modules.

Also, by increasing the number of floors for each form, nine different height models were obtained. When the number of floors is increased with tunnel form systems, it is ensured that there are no significant differences regarding architecture and statics. The shear wall elements are modelled according to minimum conditions, and their thicknesses are increased by making interventions where they
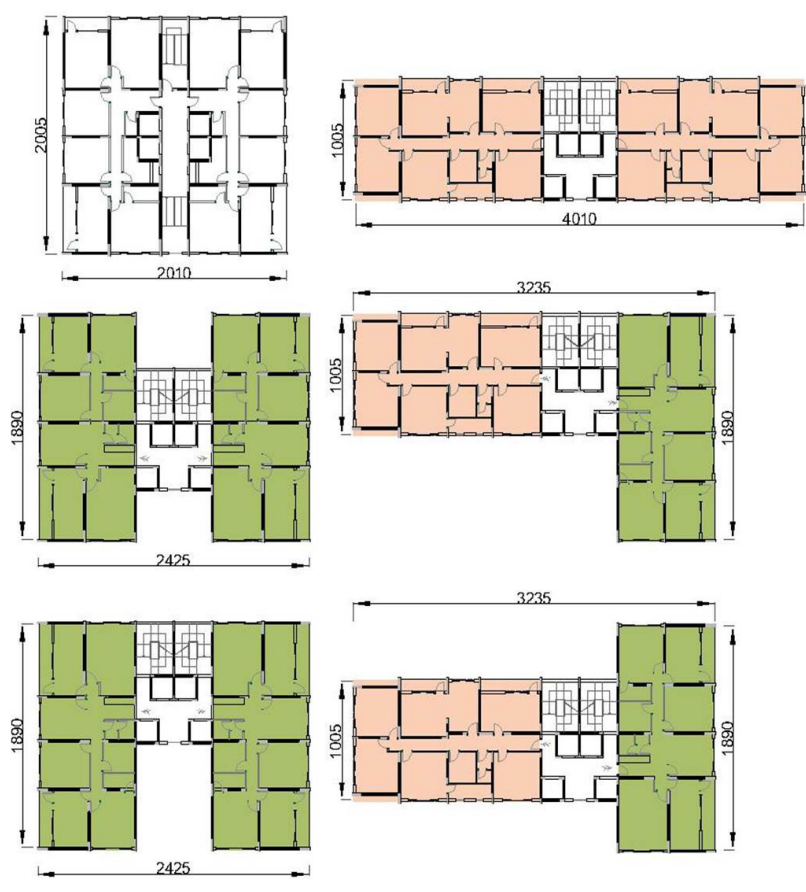

Fig. 1 Floor plans of the studied models

are insufficient. Since the load-bearing system is a shear wall system applied with tunnel form, it is not possible to change individual dimensions for insufficient elements. For this reason, the wall thicknesses of the shear wall were increased by $5 \mathrm{~cm}$, and it was multiplied in consideration of the applicability of the tunnel form (Table 1). In this process, shear wall thicknesses were obtained for which the forms can be modelled economically at different heights.

The comparison of unit costs will show how investors can realise more economical buildings, what factors will change and how costs will increase and decrease in future designs. The unit cost comparisons to be made within the scope of the study are based on the number of apartments since the architectural solutions and the net floor areas of the apartments are the same. While calculating the number of apartments to be used as residential, the architectural requirements of the projects were taken into consideration. Basement and installation storeys were included with the increase of the building height (Küçükçal1, 2007). The distribution of floors for each building height is shown in Table 1 . As a result of these changes, the number of apartments to be used as residential has been varied. Furthermore, as the number of floors increases, the total weight of the structures, and hence the amount of load to be resisted and the amount of load transferred to the foundation increases. Therefore, the types of the foundation systems vary according to the capacities, and the loads of the models in the study and these changes are considered in the cost calculations (Table 1). 
Table 1 The distribution of storeys and changing features of the models according to the number of floors

\begin{tabular}{|c|c|c|c|c|c|c|c|c|c|}
\hline & \multicolumn{9}{|c|}{ \# of floors } \\
\hline & 6 & 12 & 15 & 18 & 24 & 30 & 36 & 42 & 48 \\
\hline Structural height (m) & 16.80 & 33.60 & 42.00 & 50.40 & 67.20 & 84.00 & 100.80 & 117.60 & 134.40 \\
\hline Shear wall thickness $(\mathrm{cm})$ & 15 & 20 & 20 & 20 & 20 & 20 & 25 & & \\
\hline \# of Basement storeys & 1 & 1 & 1 & 2 & 2 & 3 & 3 & 4 & 4 \\
\hline \# of Upper storeys & 5 & 11 & 14 & 16 & 22 & 27 & 33 & 38 & 44 \\
\hline$\#$ of flat & 10 & 22 & 28 & 32 & 44 & 54 & 66 & 76 & 88 \\
\hline Installation storeys & - & - & - & - & 1 & 1 & 2 & 2 & 3 \\
\hline \# of apartments & 10 & 22 & 28 & 32 & 43 & 53 & 64 & 74 & 85 \\
\hline Foundation Types & Raft & Raft & Raft & Raft & Pile & Pile & Pile & Pile & Pile \\
\hline
\end{tabular}

In the analysis process, the performance analysis method as the static analysis method; and the bearing capacity method as a reinforced concrete design have been chosen in this study. Regarding the dynamic analysis, the Specification for Structures to be Built in Earthquake Areas (2007) was followed. Since $78 \%$ of the models in the study are over 40 meters and the same calculation method is required to be applied in all models, the horizontal loads for the models were calculated according to the Mode Combination Method given in this earthquake code.

The analysis results of the study were obtained by the Sta4-Cad program, which is a special program for structural analysis. Sta4-Cad is an integrated package program, which calculates multi-storey reinforced concrete structures' statics for earthquake, wind and reinforced concrete analysis. This program can make static and reinforced concrete analyses according to current standards and regulations. The Sta4-Cad program performs modal analysis by defining degrees of freedom according to the centre of gravity. Additionally, if it is required to calculate the stiffness centre and centre of gravity of each floor of the building, an additional moment is applied to the centre of gravity of the structure if there is a difference between these two points. In this way, an effective and realistic analysis of the structures is carried out.

It was assumed that the structures were constructed in the 4th-degree earthquake zone to reduce the effects of dynamic loads and to see the effects of plan geometry and number of floors. The earthquake zone coefficient (Ao) was chosen as 0.1 ; the soil type Z2 and the spectrum characteristic period were determined as 0.15 / 0.4 for the soil type and spectrum characteristic period (TA / TB) parameters according to the Specification for Structures to be Built in Earthquake Areas (2007). The other required parameters are as follow: structural system behaviour factor, R: 6 (shear wall structure), building importance factor, I: 1 (residential), live load factor, n: 0.3 (residential), live load reduction coefficient, $\mathrm{Cz}$ : 1 , model analysis min. load ratio, B: 0.9 (irregular structure), coefficient of soil reaction, $\mathrm{K} 0: 3000 \mathrm{t} / \mathrm{m}^{3}$, allowable safety stress in the foundation, $\sigma$ : $25 \mathrm{t} / \mathrm{m}^{2}$, earthquake load eccentricity: 0.05 . The soil parameters were accepted as medium-tight sand properties during the modelling, and it was also assumed that there was no risk of liquefaction in the ground and the groundwater level was below the foundation system (Bowles, 1996).

C30 concrete is preferred since it is not appropriate to use concrete classes under $\mathrm{C} 30$. In the reinforcement selection during reinforced concrete design, Q type steel reinforcement is used in shear walls, and Ø6, Ø28 and Ø30 flat rebar iron reinforcement are used in other elements (Institute of Turkish Standards (TSE), 2000).

Static analyses and reinforced concrete designs were made for all the projects in line with the summarised parameters; the construction costs of the load-bearing system of the projects were investigated. Effects of the other building elements whose properties vary with user preferences (for example, installation materials, surface texture, windows and doors) on the cost were not considered. The costs of structural elements used in the load-bearing system (shear walls, slabs, beams) in the superstructure and foundation were calculated from the Construction and Installation Unit Prices (2013). To investigate the financial effect of the facade area, which varies due to the change of building forms, external wall and facade insulation metrics were also assessed. Total building costs were obtained by adding wall and insulation costs, which are considered as secondary construction costs, to the load-bearing system costs.

\section{Cost comparisons}

Static, dynamic and reinforced concrete analyses were carried out according to structural criteria for the residential projects with same net floor areas and different plan 
shape geometries. Afterwards, comparisons of 54 models were made, and the approaches that can benefit the designers were explored. The load-bearing system costs of all the models are given in Fig. 2.

In Fig. 2, the cost variation due to the change in the number of floors as well as the plan shape is shown. As can be seen, load-bearing system costs vary according to geometry as the number of floors increases. The best guidance is the comparison of unit costs in obtaining the relationship among variables. The construction cost values (for example, load-bearing system cost, total cost) are divided by the number of apartments with the same net area, and the costs per apartment are compared; the variables and costs associated with the change in costs per apartment can be clearly seen. For this reason, a curve showing the variation in load-bearing system costs per apartment with increasing heights for each model is outlined in Fig. 3. A similar cost variation curve is obtained for all projects with different geometries.

If the effect of numbers of floors is examined first on the obtained curve, in the case of projects with nine different numbers of floors, the curve, which tends to decrease in the first height range, is most cost-effective at 15 -floor models and then starts to rise again. Fig. 3 shows that the unit cost decreases first and then increases again, showing a U-shaped relationship; this is in line with those obtained from the literature surveys (Çıracı, 1996; Türkel and Ergen, 2016; Newton, 1982; Harmankaya and Tuna, 2011). It has been observed that the height that gives the optimum value are the 15 -floor models, which are followed by 12 -floor models and then by 18 -floor models. However, the cost per apartment of 6-floor models is higher than other height models.

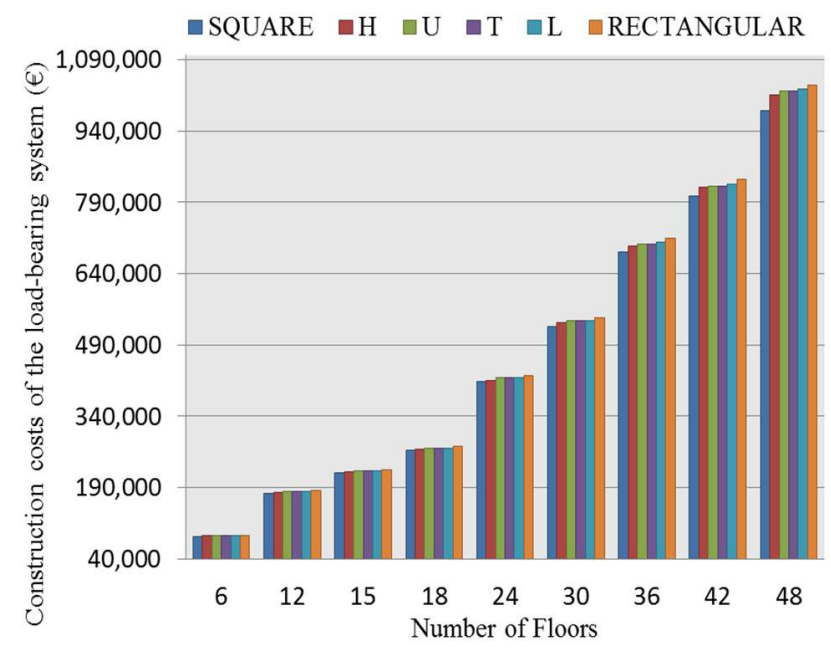

Fig. 2 Construction costs of the load-bearing system for the models varying plan shape and number of floors

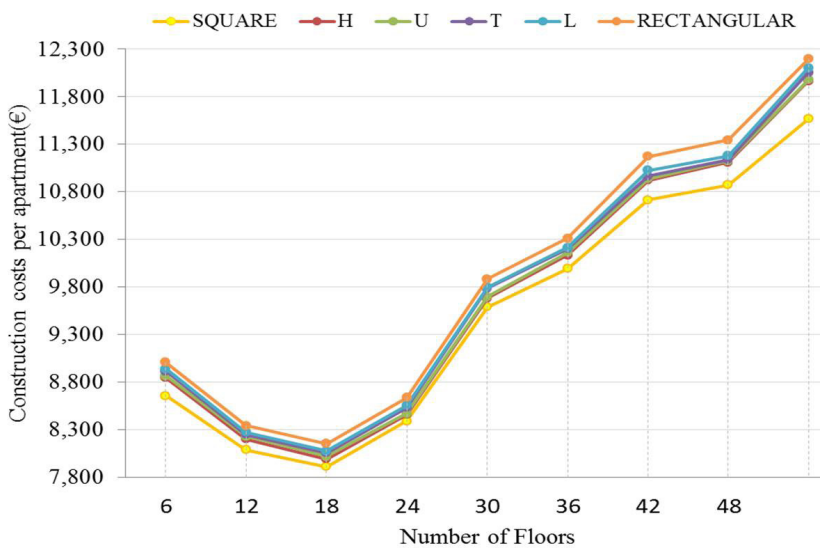

Fig. 3 Variation of Construction costs of the load-bearing system per apartment with the number of floors for various plan shapes

For the quantitative analysis, 100 units were considered as a reference value corresponding to the cost per apartment of 15-storey buildings and giving the most cost-effective figures for each form. The costs of the other models are also given in Table 2. For example, if a 48-storey building was preferred, the cost per apartment is $46.26 \%$ in square form and $49.63 \%$ in rectangular form and higher than that of a 15-storey building. Although it was solved with the minimum shear wall thickness of $15 \mathrm{~cm}$, compared to other numbers of floors; a 6-storey building is approximately $10 \%$ more costly than a 15 -storey building. Furthermore, although 12-storey, 15-storey, 18-storey and 24-storey models were solved with the same shear wall thicknesses, there is a noticeable increase in costs per apartment from 18-storey to 24-storey.

When the effect of the plan shape on cost is examined, the most economic cost regarding costs per apartment is obtained in square form. This finding is similar to the previous studies obtained for buildings produced with traditional / conventional framework systems (Wing, 1999;

Table 2 Variations in construction costs of the load-bearing system per apartment compared to 15 -storey models

\begin{tabular}{lcccccc}
\hline $\begin{array}{l}\text { \# of } \\
\text { floor }\end{array}$ & Square & $\mathrm{H}$ & $\mathrm{U}$ & $\mathrm{T}$ & $\mathrm{L}$ & Rectangle \\
\hline 6 & 109.45 & 107.86 & 107.75 & 108.11 & 108.07 & 110.52 \\
12 & 102.24 & 102.62 & 102.63 & 102.41 & 102.43 & 102.33 \\
15 & 100 & 100 & 100 & 100 & 100 & 100 \\
18 & 106.09 & 105.83 & 105.65 & 105.92 & 105.96 & 105.94 \\
24 & 121.27 & 121.15 & 120.97 & 121.53 & 121.34 & 121.23 \\
30 & 126.35 & 126.83 & 126.75 & 126.68 & 126.49 & 126.50 \\
36 & 135.47 & 136.65 & 136.39 & 136.18 & 136.54 & 137.04 \\
42 & 137.46 & 139.05 & 138.75 & 138.33 & 138.45 & 139.16 \\
48 & 146.26 & 149.73 & 149.41 & 149.68 & 149.86 & 149.63 \\
\hline
\end{tabular}


Bostancioğlu, 1999; Ibrahim, 2007; Türkel and Ergen, 2016). For the quantitative analysis of the effect of the plan shape geometry, the cost per apartment of the square form giving the most economic cost was taken as 100 units as a reference; the values of other forms are given in Table 3 accordingly. Approximately, a $0.19-5.45 \%$ increase in cost per apartment was observed due to the differentiation of the plan geometry of the forms among the models with the same floor number. Although the differences between the forms on the unit cost are considered to be negligible, when the scale is enlarged, that is, when a mass housing settlement is taken into consideration, this difference in each apartment may become significant. To discuss this subject within the scope of the study, a settlement of about 1530 houses was considered, with the forms in different plan shape geometry, and a cost comparison made. If the preference was to use a square form rather than the rectangular form, on a settlement of 55 blocks with 15 -floors, the profit obtained as a result was equivalent to the cost of the application of 48 apartments, or approximately two blocks of 15 -floors. If the same comparison was made with 18 blocks of 48 -floors between square and rectangular forms, the profit obtained when the square form was applied corresponds to the cost of approximately one block of 48 -floors.

In addition to the comparison of the load-bearing system cost including only the costs of structural elements used in superstructure and foundation, the costs of secondary construction elements, external walls and facade insulation, were also included in the calculation and compared with the total building costs. When the facade costs were added, an approximately $14 \%$ increase was observed in the cost per apartment for the square plan geometry of the 15 -floor model, which gives the most optimum results.

Table 3 Variations in construction costs of the load-bearing system per apartment relative to the square form

\begin{tabular}{lcccccc}
\hline $\begin{array}{l}\text { \# of } \\
\text { floor }\end{array}$ & Square & $\mathrm{H}$ & $\mathrm{U}$ & $\mathrm{T}$ & $\mathrm{L}$ & Rectangle \\
\hline 6 & 100 & 102.17 & 102.42 & 103.00 & 103.26 & 104.07 \\
12 & 100 & 101.42 & 101.77 & 102.00 & 102.30 & 103.17 \\
15 & 100 & 101.04 & 101.38 & 101.83 & 102.11 & 103.07 \\
18 & 100 & 100.79 & 100.96 & 101.66 & 101.99 & 102.93 \\
24 & 100 & 100.94 & 101.13 & 102.04 & 102.17 & 103.04 \\
30 & 100 & 101.43 & 101.71 & 102.10 & 102.23 & 103.20 \\
36 & 100 & 101.92 & 102.07 & 102.36 & 102.92 & 104.27 \\
42 & 100 & 102.21 & 102.34 & 102.47 & 102.85 & 104.35 \\
48 & 100 & 103.44 & 103.57 & 104.21 & 104.62 & 105.45 \\
\hline
\end{tabular}

This difference was obtained as $16.9 \%$ in the $\mathrm{H}$ and $\mathrm{U}$ forms, and $16.5 \%$ in the $\mathrm{L}$ and $\mathrm{T}$ forms, since the ratio of the facade area to the footprint area increases in the $\mathrm{H}, \mathrm{U}$, $\mathrm{L}$ and $\mathrm{T}$ forms having irregularities in the plane geometry. The rectangular form, which has the largest facade area, resulted in an increase of $17.25 \%$. The comparison of costs per apartment with the addition of external walls and facade insulation costs are shown in Table 4.

If the square form, which gives the most economical result among the forms, was considered as a reference with 100 units, the difference between the cost values per apartment for the 15-floor square form and the rectangular form increased from $3.07 \%$ to $6.28 \%$ while the cost values related to the perimeter length was added. The average difference between the $\mathrm{H}$ and $\mathrm{U}$ forms having the highest projections in the plane was $1.21 \%$; however, this difference, with the inclusion of the façade area, increased to $4.05 \%$ on average. Similar changes were observed in the $\mathrm{L}$ and $\mathrm{T}$ forms, with an increase of 2.39-3.21 \% due to moving away from the simple plan geometries and the increase of facade areas.

\section{Findings Affecting Architectural Design}

In the previous section, the effects of changes in geometrical characteristics of the housing projects produced by the tunnel form in a controlled manner were shown. However, the result of the study is to make suggestions to assist the designer in reducing the costs, especially in the architectural design phase. In this respect, the geometrical and structural criteria that are considered to affect costs in tunnel form projects are addressed.

\subsection{Effects of plane geometry on cost}

It has been showed that the effect of plane geometry on the cost of the building cannot be ignored for all the

Table 4 Variations in total building costs per apartment compared to the square form after adding facade elements

\begin{tabular}{lcccccc}
\hline $\begin{array}{l}\text { \# of } \\
\text { floor }\end{array}$ & Square & $\mathrm{H}$ & $\mathrm{U}$ & $\mathrm{T}$ & $\mathrm{L}$ & Rectangle \\
\hline 6 & 100 & 104.91 & 105.14 & 105.44 & 105.66 & 107.28 \\
12 & 100 & 104.21 & 104.52 & 104.51 & 104.77 & 106.35 \\
15 & 100 & 103.88 & 104.19 & 104.36 & 104.61 & 106.28 \\
18 & 100 & 103.64 & 103.79 & 104.20 & 104.48 & 106.12 \\
24 & 100 & 103.44 & 103.61 & 104.24 & 104.35 & 105.85 \\
30 & 100 & 103.82 & 104.07 & 104.23 & 104.35 & 105.92 \\
36 & 100 & 104.14 & 104.27 & 104.40 & 104.91 & 106.73 \\
42 & 100 & 104.31 & 104.43 & 104.51 & 104.85 & 106.74 \\
48 & 100 & 105.53 & 105.65 & 106.10 & 106.47 & 107.67 \\
\hline
\end{tabular}


different numbers of floors. The square form, which has two dimensions close to each other on the plan view, has come out as the most economic regarding cost. When the different geometries are examined, although the plane geometries are irregular, the $\mathrm{H}$ and $\mathrm{U}$ forms having two dimensions in different directions are close, (second and third closest after the square form) and are more suitable forms because of these close dimensions. The most expensive form is the rectangular form, which has the largest difference between dimensions.

The dimensional change in the plan geometrically affects the length of the perimeter. The increase in perimeter increases the facade area at the same elevation, which affects the secondary construction costs (exterior wall and facade insulation). Parallel to the load-bearing system cost, as the geometry moves away from the square form having the least circumference for the same floor area, there is an increase in the length of the facade and therefore the costs associated with the facade.

In simple and compact forms, all directions have approximately the same stiffness. However, the L, T, U and $\mathrm{H}$ forms considered in the study have sudden stiffness changes in the plan, so there is an increase in cost for these forms, which have plan irregularity. The cost variation between irregular forms has been examined in detail. The only difference between $\mathrm{L}$ and $\mathrm{T}$ forms and $\mathrm{H}$ and $\mathrm{U}$ forms is the placement of the apartments. Because of this arrangement, the projections of the forms vary. The lengths of these projections are larger in $\mathrm{L}$ and $\mathrm{U}$ forms compared to $\mathrm{T}$ and $\mathrm{H}$ forms, accordingly. The distinctive dynamic properties of these projections, which cause sudden stiffness changes in plan, cause different displacements (Ferry and Brandon, 2007). As a result of comparing the structures with the plane irregularities, costs of $\mathrm{L}$ and $\mathrm{U}$ forms are larger than those of $\mathrm{T}$ and $\mathrm{H}$ forms, respectively. Also, the impact of the facade area on the cost of the buildings has also manifested itself in these forms. The irregular outer lines and the perimeter lengths increase, and the cost difference between the L, T, U and $\mathrm{H}$ forms are affected.

As a result, the simple and regular selection of the plan will be beneficial and that the costs of buildings with simple plan forms are more cost-effective because the geometric form is the first factor in the behaviour of the load-bearing system. Attention should also be paid to minimising the proportion of the facade area to the base area in the building design, to reduce the costs.

\subsection{Effects of number of floors on the cost}

As the number of floors increases, basement storeys, installation storeys and service elements may also change (Table 1). Restrictions on these architectural requirements affect the number of apartments and therefore costs per apartment. For example, there are four basement floors in 48-storey buildings and three installation units. In tall buildings, since there is a surplus of the basement, service and installation areas, the cost of these buildings also increases. This has been addressed in previous studies and has been shown as one of the main reasons for the increase in building costs in high-rise buildings (Ferry and Brandon, 2007; Harmankaya and Tuna, 2011).

As the number of floor increases, the total weight of the structure increases, hence the amount of load that needs to be transported and transferred to the ground. With the increase in the number of floors and the increase of the structural element dimensions, the foundation solutions vary depending on the soil safety stress. Wit 6-storey, 12-storey, 15-storey and 18-storey projects raft foundations are sufficient; however, 24-storey and above projects are applied with piled foundations costing more than raft foundations. If the percentage of the foundation costs in the total cost is examined, the average cost of the raft foundation was $8.89 \%$, while the piled foundation $20.25 \%$. The effect of soil safety stress becomes even more important as the height of the structures increase. The selected ground parameters in the study are for an average soil type; however, for more unfavourable soil types, additional costs for the foundation application should be expected.

Ferry and Brandon (2007) indicated that the main reason of the cost increase with the building height is the stressing of the lower floors as they transfer the loads from the upper floors to the foundation, and large lateral loads coming from wind and earthquakes, which becomes the primary factor as the height increases. In this case, the capacities of structural elements become important. Capacities of these elements may be increased by changing the size or reinforcement layouts of the elements, or the system is strengthened with new elements. Due to the increase in floor number, shear wall thicknesses become insufficient; the shear wall thicknesses need to be increased, and hence the costs. Furthermore, as the number of floors increases, the slenderness ratios of the structures increase significantly; consequently, the structures are more stressed under horizontal loads due to the slenderness effect. As the ratio of the height to the base 
dimension increases, the tipping moment becomes more important in high-rise structures, which shows its influence in the size and reinforcement of the structural elements. Slenderness effect causes incremental increases in costs per apartment especially for projects having two apartments on one floor up to 36 floors and above.

As can be seen from the values of costs per apartment for the 6-storey buildings having the minimum number of apartments, it is not rational to build constructions with few apartments with the shear walls system and tunnel form application.

Summarising, the unit cost decreased first and then increased again after 15 storeys; a U-shaped relationship was obtained. This U-shaped relationship was also found in projects made with conventional formworks. (Newton, 1982; Çrac1, 1996). However, the situation that the minimum cost is obtained for 15 storeys is only for residential buildings produced with tunnel forms.

As a result, if multi-storey structures are preferred, the dimensions of the structural elements are changed, and the foundation systems require more costly applications such as piled foundations. Similarly, the slenderness effect, which is defined as the ratio of the height of the structures to the width of the base becomes more important, and the costs are significantly increased due to the increase in basement, service and installation areas. However, these results do not hinder the implementation of multi-storey structures today. The important point is that tunnel form applications, all of which are entirely shear-walled, are only realistic for a certain height range.

\section{Conclusion}

The aim of this study was to investigate the cost changes in reinforced concrete buildings constructed with tunnel form according to the variation of the plane geometry; that is, to take different form decisions in three dimensions and to create effective solutions to reduce building costs in architectural design phases. For the numerical research part of this study, a research group, consisting of buildings with different geometries, was established. In this group, the residential projects with the reinforced concrete shear wall bearing system applied with the tunnel form were designed. The changes in the load-bearing system and the cost values of the projects consisting of completely different geometric forms were investigated. The number of building floors was also considered as a variable, and the projects with nine different heights, from 6 to 48 floors were formed. In total, 54 residential projects were modelled with the finite element method using the Sta4Cad program, which is a special purpose structural analysis program. The aim was to try to obtain reliable and feasible projects and carry out cost analysis related to these projects. The calculations were made using the unit price method on the construction drawings. The costs per apartment of the projects with different plan shapes were compared with each other, and the relationship between the plan and the height of the building was clearly observed. The following conclusions can be drawn from this study.

- Cost increases as the difference between the lengths of the two directions in the plan increases for the models having different geometries while keeping net floor areas the same.

- With the increase in height, a U-shape curve, which decreases first to a certain floor and then increases again, is obtained. This result does not prevent the implementation of multi-storey structures today. Tunnel form applications, all of which are entirely shear walled, have proven not to be a rational choice except for a certain height range. Moreover, as can be understood from the high cost value for the cost per apartment in low-rise buildings, it is not cost-effective to apply tunnel forms with shear wall system to the buildings having few apartments.

- Resulting from the secondary construction costs analysis, which was calculated to see the effect of the facade costs on the total costs, the building costs tend to increase as the ratio of the facade area to the base area increases.

One of the basic assumptions of efficient production is the economic success of designs. This study proves that the architectural design decisions taken in the building production processes from the single structure scale to mass housing affect the building cost. Limitations have been applied in the study to investigate the financial effects of floor numbers and plan geometry and to obtain logical results. Firstly, the factors that the designer cannot intervene in such as the dependent factors in the region and settlement, climatic conditions, regional conditions, land characteristics, and various laws are not considered. Furthermore, criteria such as (i) building function, (ii) earthquake zone, (iii) soil type, (iv) concrete class, and (v) earthquake calculations, which are according to Turkish Earthquake Code are important limitations of this study. If the limit values of this data are changed, some deviation may be expected in the results. For future studies, research, within the scope 
of the residential buildings, can be expanded to different building functions (hotels, shopping centres) and the environmental, regional factors (earthquake zones, soil types). The research show the effects of plane geometry and the number of floors on costs; this may lead to improvements

\section{References}

Ashworth, A., Hogg, K., Higgs, C. (2013) "Willis's Practice and Procedure for the Quantity Surveyors", 13th ed., Wiley-Blackwell Science Ltd., Oxford, England.

Belniak, S., Lesniak, A., Plebankiewicz, E., Zima, K. (2013) "The influence of the building shape on the costs of its construction", Journal of Financial Management of Property and Construction, 18(1), pp. 90-102.

https://doi.org/10.1108/13664381311305096

Bostancıŏlu, E. (1999) "Konut Binalarının Ön Tasarımı Evresinde Maliyeti Etkileyen Faktörler ve Faktörlere Dayalı Bir Maliyet Tahmin Yöntemi", (The Factors That Affect Residential Buildings' Cost in Predesign Phase and A Cost Estimating Method that is Based on These Factors) PhD Thesis, Istanbul Technical University, İstanbul. (in Turkish).

Bowles, J. E. (1996) "Foundation Analysis and Design", 5th ed., McGrawHill, New York, USA.

Çıracı, M., (1996) "Konutlarda maliyet tahmini için bir model", (A model for cost estimation in residential buildings) Prime Ministry of Turkey, Housing Development Administration (TOKI), Housing Research Series-6. (in Turkish).

Ferry, D. J., Brandon P. S., (2007) "Cost planning of building", 9th ed., Wiley-Blackwell, Oxford, England.

Fülöp, Z. (2012) "Challenges of Structural Decisions in Contemporary Architecture", Periodica Polytechnica Architecture, 43(1), pp. 1-9. https://doi.org/10.3311/PPar.7156

Harmankaya, Z. Y., Tuna, M. E. (2011) "Türkiye'de Tünel Kalıp ile Uygulanan Çok Katlı Yapı Üretiminde Kat Adedi ve Beton Sınıfının Maliyete Etkileri", (Effects of Number of Storeys and Concrete Strength on the Building Cost of the Multi Storied Buildings Produced by Using Tunnel Form in Turkey) Journal of the Faculty of Engineering and Architecture of Gazi University, 26(2), pp. 427-433. (in Turkish).

Ibrahim, D. A. (2007) "Effect of Changes in Layout Shape on Unit Construction Cost of Residential Buildings", Samaru Journal of Information Studies, 7(1), pp. 24-31.

https://doi.org/10.4314/sjis.v7i1.40600

Institute of Turkish Standards (TSE) (2000) "Betonarme yapıların tasarım ve yapım kuralları-TS500", (Regulations for Design and Construction of Reinforced Concrete Structures-TS500) ICS 91.080.40, Türk Standardlari Enstitüsü, Ankara, Turkey. (in Turkish).

Ilerisoy, Z. Y., Tuna, M. E. (2013) "Construction Cost of Tunnel Form Buildings", Gradevinar, 65(2), pp. 135-141.

Kalkan, E., Yüksel, S. B. (2007) "Pros and Cons of Multi-storey RC Tunnel-Form (Box-Type) Buildings", The Structural Design of Tall and Special Buildings, 17(3), pp. 601-617.

https://doi.org/10.1002/tal.368 in the following: (i) renewal of the design criteria for new buildings and urban transformation processes with tunnel form applications, (ii) more efficient estimates for cost calculations, and (iii) suggestions regarding the criteria that can be taken as the basis for building at optimum cost.

Küçükçalı, R. (2007) "Yüksek Yapılarda Tesisat", (Installation Methods in Multi-Storey Buildings) Isısan Press, Istanbul, Turkey. (in Turkish).

Maver, T. W. (1970) "A Theory of Architectural Design in which the Role of the Computer is Identified", Building Science, 4(4), pp. 199-207.

Ministry of Public Works and Settlement (2013) "Yapı Yaklaşık Maliyet Birim Fiyatlar1", (Construction Unit Price) Government of the Republic of Turkey, Ankara, Turkey. (in Turkish).

Ministry of Public Works and Settlement (2007) "Specification for Structures to be Built in Earthquake Areas", Government of the Republic of Turkey, Ankara, Turkey.

Newton, S. (1982) "Cost modelling: A tentative specification", In: Brandon, P. S. (ed.) Building cost techniques: New directions, E \& F. N. Spon, London, England.

Pena, W. M., Parshall, S. A. (2001) "Problem Seeking: An Architectural Programming Primer", 4th ed., John Wiley \& Sons, Inc., New York, USA.

Safiki, A., Solikin, M., NurSahid, M. (2015) "Cost Implications of Building Design Plans: A Literature Review Analysis", In: the 2nd International Conference on Engineering Technology and Industrial Application, Surakarta, Indonesia, pp. 51-56.

Seeley, I. H. (1996) "Building Economics", 4th ed., Palgrave Macmillan, Basingstoke, United Kingdom.

STA Computer Engineering and Consulting Limited Company (2010) "STA4-CAD V13, Analysis and Design of Multi-storey Reinforced Buildings", Ankara, Turkey.

Türkel, E. B., Ergen, E. (2016) "Tünel kalıp sistemi kullanılan betonarme yüksek yapılarda, yükseklik ve kat alanı ile maliyet arasındaki ilişki", (Relationship between height and footprint area with cost for tunnel form high-rise buildings) Pamukkale University Journal of Engineering Sciences, 22(6), pp. 418-426. (in Turkish). https://doi.org/10.5505/pajes.2015.34445

Tregenza, P. (1972) "Association between building height and cost", Architects' Journal, 156(44), pp. 1031-1032.

Warszawski, A. (2003) "Analysis of Costs and Benefits of Tall Buildings", Journal of Construction Engineering and Management, 129(4), pp. 421-430. https://doi.org/10.1061/(ASCE)0733-9364(2003)129:4(421)

Wing, C. K. (1999) "On the issue of plan shape complexity: plan shape indices revisited", Construction Management and Economics, 17(4), pp. 473-482.

https://doi.org/10.1080/014461999371394 